\title{
Family challenges experienced in the care of children with special health needs
}

\begin{abstract}
Children with Special Health Needs are limited in carrying out activities of daily living, leaving them partially or totally dependent on their family members or caregivers. A descriptive study with a qualitative approach, aiming to describe and analyze the challenges experienced by family members in the care of children with special health needs. Data collection was carried out at a rehabilitation center in a state in the northeast of Brazil, from March to May 2016. It was conducted with 15 caregivers, using a semi-structured interview script. From the analysis of the speeches, three thematic categories emerged: The (re) organization of the life of caregivers and relatives of children with special needs, the context of the health care network and problems with the social network of the insertion of special needs children. The results show a predominance of caregivers, in the age group of 31 to 40 years. Mostly women, with study between six and twelve years. It is observed that special needs children change the whole daily life of the family, which needs a special adaptation to maintain integral assistance to the family, and still needs to (re) structure to maintain the family's necessary living conditions. The care and treatment provided by the reference service to the interviewed group was considered satisfactory, but these still indicate that the network does not guarantee access and care, proportional to the health needs of each user. There is difficult access to transportation for children and their caregivers. Accessibility still being a limiting issue. It is concluded, with this study, that there is a need for the social inclusion of these children, the awareness of the population in welcoming the child and the importance of socialization, so that the challenges experienced by the caregivers of these children will diminish or cease to exist.
\end{abstract}

Keywords: nursing, family, special needs children
Volume 5 Issue 2 - 2018

\author{
Sandra Beatriz Pedra Branca Dourado,' \\ Maria Liamara Alves Da Silva, ${ }^{2}$ Samara E Silva \\ Gomes, ${ }^{3}$ Suely Martins Da Silva, ${ }^{4}$ Danieli \\ Maria Matias Coêlho, ${ }^{5}$ Diego Cipriano \\ Chagas, ${ }^{6}$ Paulo Vicente Dourado, ${ }^{7}$ Geandra \\ Batista Lima Nunes, ${ }^{8}$ Elizabeth Soares \\ Oliveira De Holanda Monteiro, ${ }^{8}$ Benevina \\ Maria Vilar Teixeira Nunes 9
}

'Master in Nursing, Public Health Specialist, Estácio-Teresina College, Brazil

${ }^{2}$ Department of Nursing, Estácio-Teresina College, Brazil ${ }^{3}$ Specialist in Cardiovascular Nursing and Perfusion in Cardiac Surgery, Estácio College of Teresina, Brazil

${ }^{4}$ Master in Science and Health at the Federal University of Piauí, Brazil

${ }^{5}$ Specialist in Teaching Higher Education and Intensive Care Unit, Estácio-Teresina College, Brazil

${ }^{6}$ Nursing Undergraduate Student from Estácio College of Teresina, Brazil

7Master's Degree in Nursing from the Federal University of Piauí, Brazil

${ }^{8} \mathrm{PhD}$ student in Nursing, Federal University of Piauí, Brazil 'Department of Nursing, Federal University of Piauí, Brazil

Correspondence: Sandra Beatriz Pedra Branca Dourado, Master in Nursing, Public Health Specialist, Estácio-Teresina College, Brazil,Tel +86988539969.

Email sandradourado3@gmail.com

Received: February 23, 2018 | Published: April II, 2018

\section{Introduction}

Children with special health needs (CSHN) are those who have disabilities, be they motor, behavioral, intellectual, emotional, compromising social interaction in an egalitarian way, leaving them partially or totally dependent on their relatives or caregivers. ${ }^{1}$ These impediments, often acquired, for the survival of pathologies considered as fatal, but which for some reason survive, but with some kind of special condition. ${ }^{2}$ This group of children presents demands for specific care in the health, education and social sectors, especially children with prematurity, congenital malformations, chronic diseases, victims of trauma or other diseases acquired throughout life. ${ }^{3}$ A study conducted in the United States, in the State of California, where one in seven children have special health needs and of these, more than half have more than one chronic condition. ${ }^{2,4}$ In Brazil, the study carried out in 2006 in Rio Grande do Sul showed that 58.5\% of the children studied developed Special Health Needs (SHN) associated with perinatal factors. ${ }^{2}$

When considering the different care needs of the CSHN, Brazil has adopted a specific typology for the types of care required, being classified into five groups: development, technological, medicinal, habitual and modified. In the first, children with neuromuscular dysfunction are inserted. In the second, those dependent on technology. In the third, the drug is dependent. In the bedroom, the ones that depend on changes in the usual way of caring. And finally, children dependent on two or more groups cited. ${ }^{5}$

In relation to families of special children, they are faced with the situation of having to deal with this child, who in the great majority are (prepared) to face such difficulty, and often cause until the end of the relationship of the couple, since the whole routine changes, and as the mother's greatest caregiver is, the greater burden is placed on her, so she has to dedicate herself exclusively to this CSHN, which needs constant presence. ${ }^{6}$ The way to take care of these CSHN is a challenge, and also be related to the resources of each family. It is simile to consider that the obstacles of the day to day, make difficult the adaptations of these children in the society. Also that the life expectancy of these, has grown with the technological advances. In the care network, this care is provided by professionals, but in the home environment, they become caregivers who need permanent education to deal with children. Therefore, it is necessary for nursing professionals to be alert to seek knowledge in appropriate educational actions to help the family in the care of this CSHN. ${ }^{7}$ Therefore, the objective is to know the challenges faced by family members in the care of the CMSN, so that the professional team can mediate actions 
directed to the family caregiver and their learning demands, to care beyond survival, focusing on reducing vulnerabilities and improving the quality of life of this group.

\section{Methodological path}

This is a descriptive and qualitative research. A study carried out at the Integrated Rehabilitation Center (IRC), located in the northeast of Brazil, where medium and high complexity care is provided for people with disabilities. We interviewed 15 caregivers of children (zero to 11 years old) with special health needs. Used semi-structured interview script. The number of participants was defined by the speech saturation, identified by the researchers when the contents of their speech became repetitive. The following inclusion criteria were used: being over 18 years of age, caring for CSHN aged zero to 11 years. Caregivers younger than 18 years of age were excluded from the study, those with speech impairments, communication capacity and/or psychiatric disorders, and those whose special care is intended for people who have left the research age group of this study. The interviews were conducted in the period from 03/26/2016 to $03 / 05 / 2016$.

The semi-structured script was composed of two parts. The first one, with questions that allowed the characterization of the participants; and the second part, with open questions, aimed at stimulating the interviewee to discuss the challenges experienced in the care of children with special health needs. It is important to note that the script was pre-tested for validation of the semi-structured interview guide with two participants according to the established inclusion criteria. After the interviews were carried out, they were transcribed in their entirety and in these were marked the thematic contents that permeate the discourse on the challenges experienced, emerging the analytical categories defined for the work, in order to meet the objectives of the research. The information obtained in this study was analyzed through the thematic analysis technique, a content analysis modality first, from a reading of the plan of statements, statements and documents, to reach a deeper level, surpassing the manifest meanings of material. ${ }^{8}$

The results are presented by thematic categories, which emerged from the participants' speeches, such as: The (re) organization of the life of caregivers and relatives of children with special needs, context of the health care network and problems with the social network of insertion of the special kids. The development of the study followed the norms and guidelines of Resolution no. 466/12 of the National Health Council, which deals with the ethical aspects of research involving human beings.

Data collection was only initiated after the authorization of the institution proposed for the study and the Research Ethics Committee of the ESTÁCIO/CEUT College, with registration in Protocol No. 682/2012. Participants were offered a Free and Informed Consent Form (ICF) that informed them of the purposes of the study, informed them of the right to refuse to participate or withdraw their consent at any stage of the study, without any penalties or damages, and assured them that it would be preserved anonymity, which when the results are presented are named deponents and numbered accordingly in ascending order.

\section{Results}

The characterization of the study participants and the thematic categories emerged after transcription, reading and speech analysis, extracted through a semi-structured interview script.

\section{Characterization of subjects}

In this study, 15 semi-structured interviews were carried out with CSHN caretakers from zero to 11 years old, observing that the majority $(93.33 \%)$ were female, predominantly between 31 and 40 years old $(53.34 \%)$. Regarding schooling $73.34 \%$, between six and 12 years of study, with family income of one to two minimum wages (80\%). According to the kinship $93.33 \%$ accompanied by the mother, and $73.34 \%$ came from the state capital.

\section{A (reorganization of the life of caregivers and relatives of children with special needs}

The arrival of a child in need of special care in the family requires a reorganization of this context, with the availability of a full-time caregiver, coping with the damages of the exclusive dedication, the absence of this caregiver in the former family care and still changes in the budget composition, and all of this can directly impact the family structure. It was observed in this study that the caregivers of CSHN needed a (re) organization of their lives. What can be observed in the statements below:

[...] I had to stop working [...]. It is exclusive care, not giving more to do something else, then it is dedication twenty-four hours [...]. I am available to him for twenty-four hours, but I also have my life that sometimes I need to be absent [...] (Deponent 1).

[...] I stopped working because I have to take care of him [...] (Deponent 8).

\section{Context of the health care network}

The health care network for CSHN must be constituted at three levels of primary, secondary and tertiary care, including in the first the follow-up of home care and actions for disease prevention and health promotion; second, diagnoses and brief interventions to The provision of rehabilitation services, minimization of sequelae and improvement of quality of life. The service, treatment provided, by the service of reference to the group interviewed was considered as satisfactory in the following statements:

[...] Thank God I have the card here (IRC), because if I did not have this treatment here, I could not do it anywhere else. (Deponent 14)

[...] It's all quiet, he's being well-attended ... I do not have any complaints. (Deponent 1).

Another point to note is that users with disabilities or special health needs are more exposed to comorbidities, resulting in greater need to use health services to maintain their physical and mental integrity. The need for health care is permanent, continuous and requires more health services. However, the network may not offer access and care proportional to the health needs of each user. The deficiencies emerge in the statements of the deponents:

[...] There is enough (difficulty), I was even thinking about making a health plan for her, but still can not do it, then it's all in IRC. (Deponent3).

[...] If we go after UHS it is very difficult, so most of his appointments are required to pay for a faster result, because if you 
wait for the UHS it is very difficult. (Deponent 9).

\section{Problems with the social network of insertion of special needs children.}

To ensure qualified care, the user searches for health care and new treatment technologies, constituting as one of the first problems for a CSHN, the locomotion to the place of care. As the demand for people with special health needs is great, the means of transportation for them become insufficient, and the family seeking better quality of life for their child, funds the child's transportation. ${ }^{9}$ In the interviews that follow, the difficulty of access to transport by CSHN and their caregivers is noted:

[...] Difficult [...] to catch a bus because it does not respect, often does not show or have a ramp, if it is broken or not (Deponent 07).

[...] The locomotion because where I go I have to walk with him, have to take a bus, there it is very difficult (Deponent 11).

Accessibility is another limiting issue for CSHN, not only on the right to "come and go" or on the offer of transportation, but in the interviews carried out, it was noticed that the CSHN caregivers find obstacles related to the social awareness of the needs and limitations of the other, by respecting the special needs and legal rights of this group.

[...] (carries the child) In the arm even because he has the wheelchair more becomes more difficult because of the buses, because not everyone wants to bring a wheelchair (Deponent 10).

Another aspect voiced by the deponents in this study is the lack of awareness of the population, which often does not play its social role, described in the following testimony:

[...] I often have to change streets because sometimes there is a car parked on the ramp (Deponent 07).

\section{Discussion}

In the study, there was a predominance of caregivers aged between 31 and 40 years. This result is in line with another study on the characteristics of caregivers of children with special needs, who found the same age group among the participants, explained by several factors, including the later motherhood of women. ${ }^{10}$ In relation to kinship, the great majority of the caregivers accompanying special treatment children were mothers (14) and only one father. In the majority of the families, naturally, the women take on this activity motivated by the affective bond between mother and child, giving full care. Other members of the family, in turn, especially the companion (father), begin to assume, alone the financial responsibilities and household income.

The woman, the mother of a special child, facing a situation where the child will depend on her full care, assumes the position of caregiver. It is common for this caregiver not to feel like this, because she assumes this responsibility involved by other feelings, availability of time to care, affectivity, degree of kinship and other related feelings make the woman or mother of family take fronts of situations and to take responsibility for the care. ${ }^{11}$

Another important characteristic was the degree of schooling by the caregivers. He observed that the majority have between six of twelve years of study and even with a higher level, which increases the compression profile of the families, regarding the health orientations, that must be followed by the caregivers, fact that reveals a change, since studies indicate that the profile of these families was low schooling, and this compromised the understanding of this new phase and the assimilation of the new care that needed to be understood. ${ }^{9}$

Regarding the socioeconomic question of caregivers, among the interviewees, the majority with income between one and two minimum wages. The results of this study also coincide with the caregivers' profile in a study that found the same average salary in the study. The situation of having a CSHN, impacts on changes in the daily life of the families, leading (re) structuring to provide all the necessary supports for the continuous care of the child, causing a challenging situation for the whole family. ${ }^{10}$

The need for care and integral care often leads to the abandonment of family members' employment due to the lack of correlation between work activities and the new caregiver situation. The intense routine, demands of the whole family change in daily life, and sometimes, abandonment of employment, causing a reduction in family income, and also, overloading family members. ${ }^{3}$

Family support is the key to overcoming this new stage. The primary function of the family is caring, giving affection, attention, educating and at the same time giving a family support as a whole, a special child demands changes, as the main caretaker of this family, that father, mother, grandparents, uncles or even their brother, will have to give up his home, most of the time, in search of a better quality of life for this child. A special child ends up involving the entire family in support of this individual. ${ }^{12}$

From the challenges overcome and acceptance by the family, allows CSHN, like the family itself, to live integrated with society. ${ }^{13}$ In order to attend CSHN, it is necessary to integrate with all health services, and highlight the insertion: family and institution, because it is understood that the care network is a collective structure in which everyone participates to provide a common good. Networks are able to make the subject autonomous of their own body, thinkers and conscious of their attitudes. They aim at the man being able to have a choice and decision power, and not that he is submissive to his current health condition. ${ }^{14}$ The satisfaction of the reference service can be understood by several factors, among them: the actions developed by the Network of Care for the Person with Disabilities (RCPD) in the northeastern Brazilian state, which in the year 2015 structured their attention points, Ordinance No. 7,612 of November 17, 2011, which approved the National Plan for Persons with Disabilities, and also to Administrative Rule No. 793, of April 24, 2012, which established the network, within the UHS. In this northeastern state the network was structured by macro-region for service optimization and economy of scope, being: Coastal, Middle North, Semi-arid and Closed Macroregions. ${ }^{15}$

The health network, in accordance with UHS principles of universality, equality and integrality, guarantees children with special needs care in services at all levels, but caregivers feel more welcomed in the tertiary service, in referral services, with care Multiprofessional, differentiated, and more adequate the needs of these children, causing invisibility of these children in the levels of primary and secondary attention. ${ }^{16}$

The cost to the quality of life of these CSHN often makes families need to have financial resources for extra payments with transportation, food, medicines, and specific materials to maintain the health of that child. And even additional expenses with treatment not offered by the 
network in a satisfactory way. In addition, family income must still be considered low, and the costing of all materials, medications, and sometimes treatment becomes unfeasible or insufficient. The caregiver of this child still needs to move away from their work activities, or functions to fully dedicate themselves to the health and life situation of these children. ${ }^{9}$

The knowledge of caregivers is key to the survival of CSHN. Care and attention need to be integral, since they require care that reduces the risks associated with morbidity and mortality. Caring for their lives, the preservation of life, has a special meaning, considering the primary goal of care. However, the child will need financial and material resources that will add to the fragility of child care networks, which may expose the child to social vulnerability. ${ }^{17}$ It is similar, to consider the importance of the health care network, because without guarantee of care, the search can generate wear on the family, being important therefore the structuring of a qualified network with the purpose of promoting the prevention of injuries, treatment and adequate rehabilitation, Increasing the guarantee on the quality of life of the user. ${ }^{18}$

At present, several problems can be mentioned as impeding the insertion of children with special needs to life in society, motivated by the organization of care and UHS management, characterized by the fragmentation of services, programs, actions and clinical practices. ${ }^{19}$

\section{Final considerations}

Because it is a topic of great importance due to the number of children with special needs in Brazil as well as in a state in the Brazilian northeast, it is understood the need of research that addresses the theme with a special focus on aspects that involve access to the network, accessibility and involvement of services, family and community. It was noticed during the study, that despite the advance in terms of public health policy in the state directed to CSHN, there is still a great need for organization of the network, deserving a greater comprehensiveness on the part of the public authorities on how to guarantee access and service with quality, as well as (re) structuring the primary and secondary levels, preventing caregivers from attempting to solve all problems in the tertiary network.

Health professionals are responsible for the care, holistic care, multiprofessional care of the CSHN, so it is expected that this study may serve as an incentive for the planning of actions within the network and targeting special children and caregivers. Who often live the life of the child, thus serving as the basis for the elaboration of plans focused on the real needs of the caregivers and the CSHN. Changes such as creation of care flows, guidelines, access, regulation of services, elective medical transportation, electronic medical records, health education are necessary to make possible a qualified care and able to meet CSHN in their needs, as well as, global care, that is, child-family-service-community.

A discussion on the various segments of society and management can be carried out to determine priorities in the care of these families. The health teams of primary, secondary and tertiary care levels are responsible for articulating and implementing actions to improve the care of these individuals. As a contribution, this study allowed a greater reflection on the care provided and the challenges experienced by family members in the care of children with special health needs. As a recommendation for future work, it will be possible to verify the effectiveness of public policy actions directed at caregivers and
CSHN. It is concluded, therefore, the need for social inclusion of these CSHN, the awareness of the population in hosting the CSHN, the inclusion of policies aimed at maintaining the health of caregivers, and the importance of socialization, so that it decreases or fails to the challenges faced by caregivers of these CSHN.

\section{Acknowledgements}

None

\section{Conflict of interest}

The authors declare that there is no conflict or financial interest.

\section{References}

1. Neves ET, Cabral IE, Silveira A. Family network of children with special health needs: implications for Nursing. Rev Latino-Am Enfermagem. 2013;2(21):562-570

2. Zamberlan KC. Cotidiano de cuidado da equipe de enfermagem às crianças com necessidades especiais de saúde hospitalizadas e suas famílias. Santa Maria: Universidade Federal de Santa Maria; 2014.

3. Astolpho MP, Okido ACC, Lima RAG. Caring network for children with special health needs. Rev Bras Enferm. 2014;67(2):213-219.

4. Lucile Packard Foundation for Children's Health. Children with special health care needs: a profile of key issues. Lucile Packard Foundation for Children's Health. Children. 2010.

5. Simonasse MF, Moraes JRMM. Children with special health care needs: impact on familiar daily routine. Rev Pesqui Cuid Fundam. 2015;7(3):2202-2209

6. Barbosa MAM, Balieiro MMFG, Pettengill MAM. Family-centered care in the context of children with disabilities and their families: a reflective review. Texto contexto-enferm. 2012;1(21):194-199.

7. Silveira A, Neves ET. Crianças com necessidades especiais em saúde: cuidado familiar na preservação da Vida. Cienc Cuid Saúde. 2012;11(1):74-80.

8. Minayo MCS, organizadora. Pesquisa Social: teoria, método e criatividade. Petrópolis, Brazil: Vozes; 2001.

9. Silva EJA, Maranhão DG. Cuidados de enfermagem às crianças com necessidades especiais de saúde. Rev Enferm UNISA. 2012;3(2):117120.

10. Figueiredo SV, Sousa ACC, Gomes ILV. Children with special health needs and family: implications for Nursing. Rev Bras Enferm.2016;69(1):88-95.

11. Pimenta RA, Rodrigues LA, Greguol M. Evaluation of quality of life and burden of caregivers of individuals with intellectual disability. Rev Bras Cien Saúde. 2010;14(3):69-76.

12. Silva FHOB, Cavalcante LIC. Family Routines for Children with Special Needs in Adoptive Families. Psic: Teor e Pesq. 2015;31(2):173-80.

13. Goitein PC, Cia F. Familiar interactions of children with special educational needs: National Brazilian literature revision. Rev Sem Assoc Psicol Esc Educ. 2011;15(1):43-51.

14. Moraes JRMM, Cabral IE. The social network of children with special healthcare needs in the (in)visibility of nursing care. Rev Latino- $\mathrm{Am}$ Enfermagem. 2012;20(2):282-288.

15. Piauí. Secretaria de Estado da Saúde, Gabinete do Secretário. Resolução CIB-PI, nº 121/2015. Diário Oficial do Estado do Piauí. 2016;6:7. 
16. Ramos LDC, Moraes JRMM, Silva LF, Goés FGB.Mother's care at home for children with special needs. Invest educ enferm. 2015;33(03):492499

17. Neves ET, Cabral IE. Caring of children with special health care needs: challenges to families and pediatric nursing. Rev eletrônica enferm. 2009;11(3):527-538.
18. Pieszak GM. Implicações do cuidar de crianças com necessidades especiais de saúde: possibilidades para o cuidado familial e de enfermagem. Santa Maria: Universidade Federal de Santa Maria Santa Maria; Brazil. 2013.

19. Mendes EV. As redes de atenção à saúde. Brasília: OPAS; 2011. 